\title{
Quality of Life in Adult ADHD: A Grounded Theory Approach
}

\author{
Marios Adamou1, Sarah L. Jones ${ }^{2 *}$ \\ ${ }^{1}$ School of Human \& Health Sciences, University of Huddersfield, Huddersfield, UK \\ ${ }^{2}$ South West Yorkshire Partnership NHS Foundation Trust, Wakefield, UK \\ Email: *sarah.jones1@swyt.nhs.uk
}

How to cite this paper: Adamou, M., \& Jones, S. L. (2020). Quality of Life in Adult ADHD: A Grounded Theory Approach. Psychology, 11, 1794-1812.

https://doi.org/10.4236/psych.2020.1111113

Received: September 26, 2020

Accepted: November 27, 2020

Published: November 30, 2020

Copyright $\odot 2020$ by author(s) and Scientific Research Publishing Inc. This work is licensed under the Creative Commons Attribution International License (CC BY 4.0).

http://creativecommons.org/licenses/by/4.0/ (c) (i) Open Access

\begin{abstract}
ADHD is characterised by a persistent and impairing pattern of inattention and/or hyperactivity/impulsivity that causes significant impairment to daily life. This study explores quality of life domains in adult ADHD using grounded theory driven data collection and analysis. Three semi-structured interviews with adults with ADHD with remission of symptoms were conducted. The experience of living with ADHD was reflected in seven themes: lack of a supportive network, labelling and attitudes from others, barriers placed on interpersonal relationships, psychological responses to ADHD, loss of opportunity to fulfil educational and occupational roles, therapeutic interventions, and attitudes to medication. This narrative generates conceptual knowledge of experiences of living with ADHD in adulthood that have not previously been considered. Developing understanding of the intricacies of peoples' experiences of living with ADHD is clinically important as these specifics can help shape the variety of multidisciplinary support options.
\end{abstract}

\section{Keywords}

Adult ADHD, Quality of Life, Grounded Theory, Multidisciplinary, Clinical Psychology

\section{Introduction}

Attention deficit hyperactivity disorder (ADHD) is characterised by a persistent and impairing pattern of inattention and/or hyperactivity/impulsivity that causes significant impairment to daily life (American Psychiatric Association, 2013). Along with the main symptomatic clusters, people with ADHD may also present with neuropsychological impairments in executive functions, behaviour, and emotion regulation (Asherson, Buitelaar, Faraone, \& Rohde, 2016). ADHD is a life- 
long disorder; with patients remaining symptomatic into adulthood from childhood in approximately $65 \%$ of cases (Faraone, Biederman, \& Mick, 2006; Ginsberg, Hirvikoski, \& Lindefors, 2010; Nylander, Holmqvist, Gustafson, \& Gillberg, 2009).

Several measures are available for the assessment of adult ADHD, including diagnostic interviews, brief screening instruments, and self-report scales (Conners, Erhardt, \& Sparrow, 1999; Epstein \& Kollins, 2006; Kessler et al., 2005; Magnússon et al., 2006; Mehringer et al., 2002; Murphy \& Adler, 2004; Taylor, Deb, \& Unwin, 2011). Evidence suggests the true value of these is unknown due to persistent reporting of low quality studies (Taylor et al., 2011). Taylor's et al. (2011) review suggests that the use of measures that is derived exclusively from DSM-IV criteria, greatly restrict evaluation of the true effects of symptoms, and only provide "a snapshot" of the experience of ADHD, and therefore may obstruct clinical understanding of how approaches to treatment should be implemented.

Living with attentional problems presents a unique set of difficulties. In essence, the adult with attention problems has most likely travelled a path to other pathologies that share a common comorbidity with ADHD (Hinshaw, 1992). These may include marital conflicts, alcohol and drug abuse, anxiety disorders, affective disorders, and the possibility of developing significant personality defects, such as borderline functioning and antisocial tendencies, amongst others (Asherson et al., 2016; Fields, Johnson, \& Hassig, 2017; Kolar et al., 2008; Wender, 1995).

Health Related Quality of Life (HRQoL) is a broad construct, which aims to signify patients' subjective perception of the impact of health status, including disease and treatment, on physical, psychological, and social functioning over the lifetime (Guyatt, Feeny, \& Patrick, 1993; Leidy, Revicki, \& Genesté, 1999; Lin, Lo, Yang, \& Gau, 2015). Unsurprisingly, lower levels of HRQoL in this population have been reported (Ahnemark et al., 2018; da Silva et al., 2014; Danckaerts et al., 2010; Safren, Sprich, Cooper-Vince, Knouse, \& Lerner, 2010). Despite the fact that pharmacological treatments are very efficacious (Mattos, Louzã, Palmini, Oliveira, \& Rocha, 2012; Storebø et al., 2015), evidence of a correlation between symptomatic improvements, functional improvements, and patient reported outcomes is not consistent (Abbott, Dodd, \& Webb, 1995; Andersen, Davidson, \& Ganz, 1994; Angermeyer, Holzinger, Kilian, \& Matschinger, 2001; Breslin, 1991; Healey, Nikolic, Athanasian, \& Boland, 1997; Steele, Jensen, \& Quinn, 2006). It is reasonable to assume that a reduction in symptoms translate into immediate changes in functional or sociological measures, however this is not a consistent pattern (Rösler et al., 2013). Whilst patients can show symptomatic improvements, this does not necessarily translate to functional improvements that have a significant impact on Quality of Life (QoL) domains (Weiss et al., 2018). Interestingly, for children, maybe because of a quicker effect in reducing deficits, symptomatic improvements do appear to be 
reflected in improvements in their social and behavioural function (Buitelaar, Wilens, Zhang, Ning, \& Feldman, 2009) but for adults, these deficits are well integrated in their personality and coping mechanisms, and are thus more difficult to address.

Evaluating QoL for this population is important in order to provide the most relevant and impactful support. Several instruments have been designed to capture the effects that ADHD has on functional domains. For instance, there are five hypothesised ADHD-related QoL "areas of impact" such as: productivity, daily activities, psychological health, physical health and relationships. These concepts are measured by assessments such as the ADHD Impact Module for Adults (AIM-A) (Landgraf, 2007), the Adult ADHD Quality-of-Life Scale (AAQoL) (Brod, Johnston, Able, \& Swindle, 2006), and the Quality of Life Enjoyment and Satisfaction Questionnaire-Short Form (Q-LES-QSF) (Endicott, Nee, Harrison, \& Blumenthal, 1993; Mick, Faraone, Spencer, Zhang, \& Biederman, 2008). The majority of QoL measures have been developed using quantitative methods, and whilst useful and informative, it could be argued they can only offer only a crosssectional "snapshot" perspective of the effects of adult ADHD, thus not fully capturing QoL experiences. Further, the availability of numerous different scales to measure QoL has made it difficult to fully capture a reliable evaluation of QoL for ADHD in adulthood (Agarwal, Goldenberg, Perry, \& IsHak, 2012). Additionally, from our observations, psychiatric measures have generally been produced from the perspective of mental health professionals, with further development and validation from mixed psychiatric groups, with a variety of comorbidities, and validation measured by general population samples. Because of this, there is a certain amount of item redundancy across measures, making it uncertain which issues and domains are relevant specifically to people with adult ADHD. The items across each of the questionnaires are framed in a very general manner and perhaps the relationship between the items and responses is assumed to be due to ADHD.

It has been suggested that qualitative work that has been conducted is either not from an individual perspective (Finzi-Dottan, Manor, \& Tyano, 2006), or applies limited methodology in expanding the meaning of QoL issues to patients (Gingrich, Liu, Cascio, Wang, \& Insel, 2000). However, a number of useful studies employing various qualitative methods have emerged (Brod, Schmitt, Goodwin, Hodgkins, \& Niebler, 2012; Henry \& Jones, 2011; Michielsen et al., 2015) which suggest adults with ADHD have lower QoL compared to normative populations (Agarwal et al., 2012; da Silva et al., 2014; Lin et al., 2015). To build on this, development of a QoL narrative in adult ADHD should be from a bottom up perspective, starting with qualitative interviews with people with the disorder (Hooley, 1985), which is not necessarily how previous work has been conducted. The majority of current methodologies mainly apply QoL measures developed from a top down perspective using judgements from people rather than the patient population. Also, the qualitative research carried out in this area 
tends to focus on the experience of receiving a diagnosis (Brod, Schmitt et al., 2012; Hansson Halleröd, Anckarsäter, Råstam, \& Hansson Scherman, 2015; Henry \& Jones, 2011; Michielsen et al., 2015). However, what we are interested in here is the experience of living with ADHD in adulthood and the impact on functional life domains.

This study applied grounded theory (GT) methodology to the analysis of interviews with people with a confirmed diagnosis of adult ADHD in order to elicit subjective reflections regarding the impact of adult ADHD on HRQoL. The aim here is to deepen the narrative, expand our knowledge of subjective experience and develop greater awareness of how QoL is affected in adult ADHD, and of how we can apply this to clinical decision-making and care planning.

\section{Methods}

\subsection{Sample}

Three patients with a diagnosis of ADHD were invited to participate to the study (see Table 1). The patients interviewed were two women aged 35 and 55 years old and one man aged 57 years old. All were diagnosed with ADHD for the first time approximately three years before the interview, and all had remission of ADHD symptoms by pharmacotherapy. Of these, none had any other comorbidity or substance misuse. This number of patients was considered appropriate as it was expected to produce adequate amount of data for textual analysis (Giorgi, 2008). Should data saturation not be achieved, further interviews would be scheduled.

\subsection{Methodology}

The current study used the GT approach (Glaser \& Strauss, 1967; Glaser \& Strauss, 1965). The term reflects the concept that theory emerging from this type of work is grounded in the information gathered directly from a target group of individuals, and places emphasis upon the individual's account of their experience

Table 1. Participant characteristics.

\begin{tabular}{cccc}
\hline Patient ID & $\mathbf{1}$ & $\mathbf{2}$ & $\mathbf{3}$ \\
\hline Gender & Female & Female & Male \\
Age & 55 & 35 & 57 \\
Duration of ADHD (years) & 50 & 29 & 2 \\
Duration since diagnosis (years) & 2.5 & 3 & Yes \\
Pharmacological treatment & Yes & Yes & No \\
Employment & Yes & Yes (part-time) & Own (wife's) \\
Accommodation & Own & Rented & Spouse \\
Living status & Spouse & Alone & Secondary \\
\hline
\end{tabular}


(Pidgeon, 1996). GT is an appropriate approach for conducting research with no strong theoretical basis (Pidgeon, 1996), and is aimed at analysing data rather than a specific technique of data collection (McCleod, 2001). However, data collection for GT involves an iterative process in which data from one interview is analysed before conducting the next interview. From this, it is possible to introduce information into subsequent interviews, which is "grounded" in the information collected from earlier interviews.

\subsection{Procedure}

In setting up the interviews, the prospective participant received a letter outlining the study, the researcher followed on the letter with a telephone call. Once the interview process had been explained, participants were asked to allow at least two hours for the interviewing process which would include the introduction and de-briefing. They were informed that a confirmation letter with a consent form and other interview materials would be sent by post and asked to read the information and sign and return the consent form prior to the interview. All consenting participants were interviewed in a non-medical environment, in the Library of the Hospital. Before commencing the interviews, participants were given the opportunity to ask questions. They were also informed that at the end there would be time for de-briefing.

For this study, the interview questions were focused questions to invite detailed topic discussion. By creating open-ended, non-judgmental questions, the emergence of unanticipated statements were encouraged. The combination of how the questions were constructed and how the interview was conducted shaped how well the balance between making the interview open-ended and focusing on significant statements was achieved.

\subsection{Data Analysis}

The text was closely inspected on a sentence-by-sentence basis, which resulted in the generation of several themes. Themes that arose were consistent across interviews. An indexing system of themes was generated with cross-references between themes and specific interviews and points in the text where the theme emerged. The aim of this process was to arrive at a range of indicators, which reflected the impact of adult ADHD on HRQoL domains. The whole process was iterative, starting with transcription of the interviews, highlighting pointers on the interview transcripts, writing memos, linking themes together, arriving at core themes, and further integration of categories by creating links between them and defining what the core themes were. The process was repeated until the researcher arrived at the stage where no further themes emerged, and saturation point was reached. The use of software Atlas version 5 allowed the data to be collected, connected, visualised, analysed and explored.

At cessation of the third interview, it was clear that no further novel themes had emerged so no further interviews took place. With a high level of concor- 
dance between interviews, it was felt at this point that sufficient data saturation had been achieved. Using the coding method mentioned above, the first cycle of coding produced 356 codes from all the three interviews. The codes were then analysed (second cycle of coding) and those that related to a common theme were grouped together. These themes were then grouped and regrouped to find the higher order commonalities or categories and seven of these were identified.

\subsection{Ethical Considerations}

The study was approved by the East Kent LREC (Reference: 07/Q1803/39). All participants gave written informed consent.

\section{Results}

From the process detailed in the data analysis section, seven themes emerged which represented HRQoL domains. The emerging themes were 1) lack of a supportive network 2) labelling and attitudes from others 3) barriers placed on interpersonal relationships 4) psychological responses to ADHD 5) loss of opportunity to fulfil educational and occupational roles 6) therapeutic interventions, and 7) attitudes to medication. Each theme is detailed below with a selection of representative quotes. Each quote is preceded by a number that designates which interview the quote was taken from (ie I1, I2).

\subsection{Lack of Supportive Network}

In conditions of ill health, within the cultural context of this study, the expectation is that family and society have a supportive role. Despite stigmatisation, this is expected for mental health conditions as well. Respondents report that they do not have a wide support network, particularly in the adult years. In contrast, they seem to be experiencing active resentment from the family which does not decrease as years progressed, possibly because of lack of diagnosis (and thus understanding) of ADHD. Lack of education and direct comparison with siblings, add to the feeling of being different and isolation. Friends seem to be fewer in number than normally expected and patients seem not to be able to provide as much support themselves. Unlike other mental health conditions, where a "normal" baseline had been achieved which allows for relationships to be formed, the person with ADHD does not have this opportunity. Furthermore, the lack of an identifiable time period where a change which differentiates the individual's mental state takes place, does not allow friends to attribute the change externally for example, as in schizophrenia. On the contrary, they are likely to directly "blame" the person with ADHD for what he is rather than a mental health condition such as ADHD for any problems. Men may find refuge in the cultural stereotype of the supporting wife and may therefore increase the possibility of success whilst for women, the outcome may be worse in all areas.

I.1 "I feel it was a bitter disappointment to my Mum and Dad... I found it 
very difficult during school to maintain friendships and to have friendships... found it difficult to mix in the playground or anything... I wasn't part of a crowd at all...I was incredibly shy".

I.2 "I am who I am and I don't need any friends... I was the only one of three kids who was demanding...I was viewed as the black sheep of the family... you don't have as many friends as other people so your network of friends is quite small... at school, family, peers, everybody else say you are not like us... actually I remember the day that you (mother) told me that no one wanted me in the house and that I was noisy".

I.3 "I was being cloaked in something else so that the other children wouldn't start calling me names or wouldn't start pointing fingers at me... the teacher was really ruthless... we can't plate that on our little J... and my mother was always worried about, well we don't want him to be perceived as being abnormal... this causes, in effect, to be branded and therefore ostracised within the classroom or within whatever social... (parents) didn't want to see me as being dumb... not really being supported, except for my mother's desire to push me... there are several women in my life that would have been great mothers for me... I lean upon her (wife) and she supports everything and it's a lot of stress, it's a lot of stress on her".

\subsection{Labelling and Attitudes from Others}

Respondents report they had uniquely lonely life. Early on, not only did they experience rejection (being different, not understood) from peers but also been the victims of relentless and continuous bullying. The feeling of "not being part of" developed alongside low self-esteem. Education also suffers not just because of cognitive deficits such as inattentiveness, but primarily by the inability to adapt to a hostile schooling environment.

I.1 "I was school-phobic and looking back now it was pretty clear why... I'd always been labelled lazy...I'd always been told I was rubbish and all this and that... I was most definitely a hard, pretty hard nut... Nasty bullying yeah, which is what kids are like aren't they.

I.2 "Rather than being told that you are stupid... you have to become quite hardy as a person with ADHD and have wide shoulders because you have to let things bounce off you...I think sometimes it is lonely being me... you have to have a support network, because you will do things that you will need to turn around and say to somebody, "help!"...(there are) people out there who have had horrible things said to them because people don't understand, you're stupid, you're thick, all the horrible kid names that kids don't want to hear".

I.3 "I was just withdrawn... or you're this one or you're that one or the stupid one, so you hear all the names. You hear all the callings; you hear all the classifications that you're the dumb one or whatever... it lasts a lifetime". 


\subsection{Barriers Placed on Interpersonal Relationships}

Respondents early on in their lives indicate that generally they feel different from their siblings and peers. This they have not been able to explain or explain away, so they have to carry the emotional consequences of the efforts of family, educational, occupational and playground-societal system to "put them right" as they progressed through life. If they choose to defend against efforts, two outcomes emerge: depression or defiance. As these outcomes progress, two types of barriers on interpersonal relationships are erected: internal (from the person) in the form of isolation and fear of engagement and external (from others) who reject, label and run away. These barriers set a context of low self-esteem, frequent rejections and myriads of negative cognitive core beliefs. These barriers express themselves to all areas of life (occupation, personal relationships etc.) and are seen as a primary hindrance in the wellbeing of the person with ADHD.

I.1 "I probably was on another planet... they'd believe I was a bit thoughtless or a bit selfish or didn't, don't listen is quite a very common one... I've made some really unsavoury choices... I feel it was a bitter disappointment to my mum and dad...”.

I.2 "You are viewed as defiant although I don't think that you are purposely defiant, it is just who you are... my life is very different to my siblings in that I didn't finish school. It changed everything that I got into as a young adult... everybody else sees that you are different... I don't know how to be a team player...I don't know how to act appropriately when somebody pisses me off...sometimes it is easier to not socially interact with people because it is difficult, because people annoy me... just do what you want to do... throughout your whole life you just do things without having to rationalise it... I think emotionally you're majorly unbalanced with ADHD".

I.3 "I couldn't do what was necessary... it was distracting for the teacher, it was distracting for me... not able to do what would enable me later in adulthood to be acclimated into society... you're the last person to some extent... you don't act naturally.... it's damaged, there's other Men you know... they see the ADHD as being something that's just, there's something wrong with the person, there's something wrong with that Man".

\subsection{Psychological Responses to ADHD}

Respondents report that ADHD affects their psychological makeup in a negative manner. Isolation by peers, rejection by family and sometimes open hostility make the person unhappy during childhood. This feeling does not go away during adulthood and indeed for some people can lead to severe clinical depression. Feelings of resentment about the way a child with ADHD is treated can sometimes lead to feelings of anger which also carry on to adulthood. The person with ADHD has to cope primarily with two emotions: depression and anger.

I.1 "I was really very angry... have a lot of temper tantrums... I had a break- 
down... I was incredibly shy... believe I was a bit thoughtless or a bit selfish... I was quite ambitious.... I was fairly independent and ambitious".

I.2 "I was a rebellious kid really...viewed as defiant...I was getting up to mischief... rather than being unhappy and sitting and trying... emotionally you're majorly unbalanced with ADHD... you have this tenacious ability that makes you keep going and makes you block things out... you have more energy, I think, than a lot of people... it affects your sense of self... It is all the negativity that builds up... you have to become quite hardy as a person with ADHD...”.

I.3 I was becoming isolated... I suffered... issues of feeling that I was left out... I was just withdrawn... the emotional values that you, you, you, you, you become neglected... there's a certain hesitation in everything you do... the damage has resulted in me putting major bands of tape over this leakage...”.

\subsection{Loss of Opportunity to Fulfil Educational and Occupational Roles}

Respondents report that they are not able to achieve educational and occupational roles, not only because of lack of ability but also as a result of the negative response from teachers, employers and peers. Educationally, there were held back by the system who gave up on them early on. As a result, they would drop out of school at worse, have a bad experience of learning and education at best, both of which would disadvantage them later on in life.

Occupationally, they report difficulties fitting in with colleagues, performing at an adequate level and responding to employers' needs.

I.1 "It was the schooling part that made me feel that I'd missed out... I dropped out of school, I dropped out of secondary school, I dropped out of college... I could not keep up with the workload... Courses are a nightmare for me now... I'd got the ability to do it but as the years progressed I was getting further and further behind... I think that was quite damaging. At sixteen I had a breakdown... (work) I suspect it was more stress for me... I think I probably avoided it more... you know you do all that and you do all this and you do all that teaching and you can't do a timesheet...".

I.2 "My life is very different to my siblings in that I didn't finish school... If you put me in a room with people where I have to be part of a team it is not going to work... if people don't understand what you have, they don't know how to work with you".

I.3 "I would find I was being held back and I was starting to be isolated and therefore I was put into a remedial school... I was quite like, well it was, it's almost like you were being somewhat institutionalised at a young age, into this way of being classificated... my problem was my homework and my problem was my intellectual skills that were not being able to focus within the system... they held me back in one year... there is a certain hesitation in 
everything you do because you don't know if you are doing it right... you don't have those fundamentals down in the correct way... I have missed opportunities and opportunities did, have been gifted to me, I haven't been able to fully utilise them... everything has fallen through the hands and fallen through... I have been given tremendous opportunities and I've lost them... people will look at me and go, my God you're a disaster... that was just trying to ruin your career... with how many times I was told with a job, we're having problems here, I don't think this is gonna work out for you".

\subsection{Therapeutic Interventions}

Respondents had a pretty good idea what interventions they thought would be most helpful. They thought on demand problem solving interventions targeting practical everyday life issues would be beneficial. Furthermore, involvement of people with ADHD as part of the Service Team to act as role models, but also to facilitate engagement, was also highlighted. From the more "formal" psychological treatments, family therapy was seen as the most important.

I.1 "I think relationships help, certainly you, know counselling for relationships, specifically knowing that there is an ADD element there and the traits of ADD... On the education side, just definitively there's something on the shelves that I would want there... money management I think is a major one... more assessment at school and more screening... coaching in specific areas that that particular person needs or wants...".

I.2 "As an adult, need counselling to deal with things that have happened in the past and for you to understand why these things have happened... you need group work so that you can learn to form relationships with people and trust each other... some sort of training, or a mentor... problems with housing, with medical issues, with all sorts of things that need some sort of support... you work out coping mechanisms for things and you have diaries to do whatever... the bigger things are having a normal life... a holistic overview... yes, it's everything. It's housing, it's money, it's education, it's relationships. It's the whole lot... If family therapy was undertaken first and foremost to keep the family together... and to come to some sort of compromise about how you are going to live in harmony with one another, that would then impact on the bigger picture really...”.

I.3 "It would have been nice to have somebody that had ADHD okay, and therefore that person could hear and say look there's nothing that I'm telling you that you haven't heard before... having Seniors that have ADHD that have gone through... you need to set yourself off on this pathway with the, with the certain, I'd say domains, being i.e. medicated or i.e. in a structure so that you can express yourself to this outside world... and you need to provide direction for them... you have to have people on the staff that have gone through these pathways...". 


\subsection{Attitudes to Medication}

The participants have an overwhelmingly positive attitude to medication. They consider it as the primary intervention and almost as a sine qua non for success. No controversy or argument is posed as to its efficacy and no complaints about side effects. The effects described are more frequently for symptom reduction but on many occasions for the "benefit" of other people as well.

I.1 "I trialled a couple of my daughter's tablets and actually found, wow, goodness me, this has helped me... I was able to manage my workload more effectively; I was able to plan more effectively... my life wasn't as chaotic, that's how I would say. I was able to write more, can't think of the word. When I was writing things I was far more ordered, far more ordered in my writing and I was able to listen more effectively at meetings... if I'm not on my medication I can be a little bit all over the place...I think I'm a lot more amenable when I'm with somebody and I can listen more effectively, have a better rapport...will you just take your tablets please because you are driving me round the bend here?... I probably miss a lot I would imagine".

I.2 "So the prescription helped me do my work... it helped me move up in terms of education and learning and things like that...".

I.3 "Use the medication to push forward...the medication would have helped me absolutely... without medication they (children) are gonna hit the wall or they're gonna hit that wall and they're gonna hit it... being non-medicated was, was terrible... the medication has allowed me to stay on point and not give up".

\section{Discussion}

This study focused on the qualitative accounts of three people with a diagnosis of adult ADHD. The main aim of the study was to elicit a series of individual accounts regarding the impact of adult ADHD on HRQoL and to determine what commonalities lay between these individuals. Although ADHD is often perceived as a disorder of childhood, its impact on HRQoL in adulthood has shown to be significant, as evident from the narrative derived in this study. As previously described, the domains which appear in the majority of HRQoL measures that have been applied in adult ADHD, have largely not been determined by people with the disorder. The present study provides a description of seven life domains that were independently defined by the participants in the study, allowing for a bottom-up approach.

Regarding comparisons with domains from quantitative QoL measures, there is some consistency with the type of domains expressed. For instance, the loss of opportunity to fulfil educational and occupational roles was a theme extracted in this study. This is in line with other research that found reoccurring themes of less financial stability, and lower educational achievement for ADHD compared to neuro-typical profiles (Brod, Pohlman, Lasser, \& Hodgkins, 2012; Brod, Schmitt et al., 2012; Hansson Halleröd et al., 2015). However, interestingly, sev- 
eral domains that are not commonly defined as problematic for this group but are subjectively important to the participants in this study, were identified here. Specifically, the lack of a supportive network, labelling and attitudes from others, and barriers placed on interpersonal relationships, are not fully captured by usual measures. By this omission, useful interventions which would have a direct effect in the HRQoL of adults with ADHD, can be missed.

To the best of our knowledge, the significance of a lack of a supporting network, and labelling and attitudes from others, has not been discussed in relation to ADHD in adulthood to the same lengths that it has been discussed in other disorders, such as schizophrenia for instance. However, our findings suggest that a negative emotive experience similar to that of Expressed Emotion (EE) seems to exist in the environment of the person with ADHD, which is supportive of previous studies that identify a connection between EE and ADHD (Baker, Heller, \& Henker, 2000; Daley, Sonuga-Barke, \& Thompson, 2003; Peris \& Hinshaw, 2003; Psychogiou, Daley, Thompson, \& Sonuga-Barke, 2007). EE in the context of schizophrenia, reflects the attitude of a close relative towards a schizophrenic family member and has been well studied (Brown, Birley, \& Wing, 1972; Brown, Monck, Carstairs, \& Wing, 1962) and reviewed (Hooley, 1985). In schizophrenia, the attitude of family members is affecting the course of the condition (at least in the short term). A similar notion has been explored in ADHD, however, there is some debate as to whether or not EE has a causal role in $\mathrm{ADHD}$, or if EE is heightened due to the potential difficulties associated with supporting a person with $\mathrm{ADHD}$, particularly in genetic sub-groups (Sonuga-Barke et al., 2008). However, there is evidence to suggest that reductions in ADHD symptoms are associated with reductions in parental negativity towards the child (Barkley \& Cunningham, 1979; Barkley, Karlsson, Pollard, \& Murphy, 1985; Schachar, Taylor, Wieselberg, Thorley, \& Rutter, 1987). Further, in a more recent study, Musser, Karalunas, Dieckmann, Peris \& Nigg (2016) found that ADHD symptom reduction is less likely to occur if higher levels of parental criticism is evident, thus suggesting that EE does not play a causal role in ADHD. Instead, it is likely that heightened levels of EE exasperate the situation, having the potential to increase the severity of symptoms and persistence of the disorder into adulthood. In contrast with schizophrenia, in ADHD, EE starts in childhood (the median age of onset of ADHD is seven years) (Kessler et al., 2005), remains present for longer than in schizophrenia which also starts later in life, schizophrenia first appears in men in their late teens or early twenties and in women their twenties or early thirties (Robins \& Regier, 1991). The significance of this early EE in people with ADHD is still relatively unknown despite the fact that this interaction may permanently affect the person's neurobehavioral control systems, longitudinal research will facilitate this further.

Barriers to interpersonal relationships of adults with ADHD have not been discussed in detail. Even the common and accepted psychological work that relates to attachment theory which has taken place extensively in other conditions 
such as depression (Goldberg, Muir, \& Kerr, 2000), is minimal in ADHD. Attachment research so far has rarely focused on ADHD, thus ignoring a central component of social and emotional development of an individual. The few studies that have taken place so far in relation to attachment theory and ADHD, simply serve to capture the existence of attachment problems in relation to ADHD. This is of course important because it can support an attachment problem-expressed emotion pathway, but the studies are very few indeed. Interestingly, Niederhofer (2009) reported that from 79 insecurely attached patients, 72 presented ADHD-like symptoms, thus setting the scene. When adult patients with ADHD were studied, there was an association with partly adverse parental rearing styles, current attachment problems in romantic partnerships and emotion regulation disturbances when compared with adult ADHD patients who did not have a parent with ADHD (Edel, Juckel, \& Brüne, 2010). In another study, ADHD diagnosis was independently associated with parent-rated child behaviour problems (Green, Stanley, \& Peters, 2007). Not only the existence but also the severity of symptoms is relevant in the attachment. The prevalence of maternal insecure and unresolved attachment representations increases with the degree of severity of children's ADHD symptoms (Kissgen et al., 2009) and the disruption of attachment may be an important feature that underlies the wide range of symptoms that are typically found in youths with Conduct Disorder in childhood (Holland, Moretti, Verlaan, \& Peterson, 1993). How this is tackled by parents is also important: parental promotion of autonomy in children with temperamental emotionality predicted anxious attachment, while parental restriction of autonomy in children with high levels of temperamental activity predicted avoidant attachment (Finzi-Dottan et al., 2006). The current literature supports that early on in the development of a toddler with ADHD there are changes in the nature of the attachment. It is proposed here that this could also be an effect of the person with ADHD on the attachment because of an impairment of their dopaminergic system. Interestingly, dopamine D2 receptors (which are implicated in ADHD) in the nucleus accumbens are also important for social attachment in female prairie voles (Gingrich et al., 2000) and dopamine D4 receptor (DRD4) (again implicated in ADHD) gene polymorphism is associated with attachment disorganisation in infants (Lakatos et al., 2002; Reiner \& Spangler, 2010). These studies suggest that an imbalance in the dopaminergic system of the child may contribute to the attachment problems and theoretically, an infant with ADHD may be more at risk to be contributing negatively to this attachment. Hence on this occasion, a one-way cause-and-effect explanation of attachment impairment between parent and toddler with ADHD cannot be made. The observation that experiences of barriers towards interpersonal relationships is a real-life issue for the participants in this study, demonstrates the need for a further in-depth examination of not only the aetiology of the disorder, but how the experience of living within it needs to be supported comprehensively. 


\section{Conclusion}

HRQoL in adulthood ADHD was reflected in seven themes: lack of a supportive network, labelling and attitudes from others, barriers placed on interpersonal relationships, psychological responses to ADHD, loss of opportunity to fulfil educational and occupational roles, therapeutic interventions and attitudes to medication. Whilst this study supports previous research that produce similar domains of concern, the methodological approach employed here has allowed the research to elicit subjective reflections regarding the impact of adult ADHD on QoL that have not previously been identified. Thus, it has allowed for a greater awareness of how QoL is affected in adult ADHD. Understanding the intricacies of peoples' experiences of living with ADHD in adulthood is clinically important; these details can help shape the variety of multidisciplinary support options that may be of benefit to patients, which is of primary importance. The narrative here reflects the evidence that experiences of ADHD do indeed result in a lower QoL (Ahnemark et al., 2018; da Silva et al., 2014; Danckaerts et al., 2010; Hansson Halleröd et al., 2015; Safren et al., 2010), yet has demonstrated the importance of implementing qualitative approaches to deepen our understanding. Continuing to develop this narrative is important; especially because ADHD symptomology presents differently in adulthood compared to childhood (Brod, Pohlman et al., 2012) and should be explored in its own right.

Naturally, whilst our findings are important, they are not generalisable per se. Future studies would benefit from larger samples and may endeavour to focus on cultural considerations, particularly between Western and Asian cultures, that would facilitate culturally sensitive narratives. However, interestingly, Brod, Pohlman et al. (2012) explored the burden of illness for adults with ADHD across seven Western countries and found similar themes across nations, suggesting that ADHD affects people similarly regardless of societal backgrounds. The current quantitative literature suggests that deficits in adults with ADHD can be attributed to specific functional impairments as a result of dysfunction in brain circuits. The data from this study suggest that problems with attachment, high expressed emotion and lack of choices can not only account for much of the ADHD symptomatology, but may indeed be causal. By exploring these avenues therapeutically, it is possible that the effects of ADHD symptomatology can be minimised.

\section{Data Availability Statement}

The data that support the findings of this study are available from the corresponding author upon reasonable request.

\section{Ethics Approval Statement/Patient Consent Statement}

The study was approved by the East Kent LREC (Reference: 07/Q1803/39). All participants gave written informed consent.

\section{Conflicts of Interest}

The authors declare no conflicts of interest regarding the publication of this paper. 


\section{References}

Abbott, J., Dodd, M., \& Webb, A. K. (1995). Different Perceptions of Disease Severity and Self Care between Patients with Cystic Fibrosis, Their Close Companions, and Physician. Thorax, 50, 794-796. https://doi.org/10.1136/thx.50.7.794

Agarwal, R., Goldenberg, M., Perry, R., \& IsHak, W. W. (2012). The Quality of Life of Adults with Attention Deficit Hyperactivity Disorder: A Systematic Review. Innovations in Clinical Neuroscience, 9, 10-21. https://pubmed.ncbi.nlm.nih.gov/22808445/

Ahnemark, E., Di Schiena, M., Fredman, A. C., Medin, E., Söderling, J. K., \& Ginsberg, Y. (2018). Health-Related Quality of Life and Burden of Illness in Adults with Newly Diagnosed Attention-Deficit/Hyperactivity Disorder in Sweden. BMC Psychiatry, 18, Article No. 223. https://doi.org/10.1186/s12888-018-1803-y

American Psychiatric Association (2013). Diagnostic and Statistical Manual of Mental Disorders (5th ed.). Arlington, VA: APA. https://doi.org/10.1176/appi.books.9780890425596

Andersen, R. M., Davidson, P. L., \& Ganz, P. A. (1994). Symbiotic Relationships of Quality of Life, Health Services Research and Other Health Research. Quality of Life Research, 3, 365-371. https://doi.org/10.1007/BF00451728

Angermeyer, M. C., Holzinger, A., Kilian, R., \& Matschinger, H. (2001). Quality of Life-As Defined by Schizophrenic Patients and Psychiatrists. The International Journal of Social Psychiatry, 47, 34-42. https://doi.org/10.1177/002076400104700203

Asherson, P., Buitelaar, J., Faraone, S. V., \& Rohde, L. A. (2016). Adult Attention-Deficit Hyperactivity Disorder: Key Conceptual Issues. Lancet Psychiatry, 3, 568-578. https://doi.org/10.1016/S2215-0366(16)30032-3

Baker, B. L., Heller, T. L., \& Henker, B. (2000). Expressed Emotion, Parenting Stress, and Adjustment in Mothers of Young Children with Behavior Problems. Journal of Child Psychology and Psychiatry, 41, 907-915. https://doi.org/10.1111/1469-7610.00678

Barkley, R. A., \& Cunningham, C. E. (1979). The Effects of Methylphenidate on the Mother-Child Interactions of Hyperactive Children. Archives of General Psychiatry, 36, 201-208. https://doi.org/10.1001/archpsyc.1979.01780020091010

Barkley, R. A., Karlsson, J., Pollard, S., \& Murphy, J. V. (1985). Developmental Changes in the Mother-Child Interactions of Hyperactive Boys: Effects of Two Dose Levels of Ritalin. Journal of Child Psychology and Psychiatry, 26, 705-715. https://doi.org/10.1111/j.1469-7610.1985.tb00585.x

Breslin, S. (1991). Quality of Life: How Is It Measured and Defined? Urologia Internationalis, 46, 246-251. https://doi.org/10.1159/000282146

Brod, M., Johnston, J., Able, S., \& Swindle, R. (2006). Validation of the Adult Attention-Deficit/Hyperactivity Disorder Quality-of-Life Scale (AAQoL): A Disease-Specific Quality-of-Life Measure. Quality of Life Research, 15, 117-129.

https://www.jstor.org/stable/27641069

https://doi.org/10.1007/s11136-005-8325-Z

Brod, M., Pohlman, B., Lasser, R., \& Hodgkins, P. (2012). Comparison of the Burden of Illness for Adults with ADHD across Seven Countries: A Qualitative Study. Health and Quality of Life Outcomes, 10, Article No. 47. https://doi.org/10.1186/1477-7525-10-47

Brod, M., Schmitt, E., Goodwin, M., Hodgkins, P., \& Niebler, G. (2012). ADHD Burden of Illness in Older Adults: A Life Course Perspective. Quality of Life Research, 21, 795-799. https://doi.org/10.1007/s11136-011-9981-9

Brown, G. W., Birley, J. L., \& Wing, J. K. (1972). Influence of Family Life on the Course of Schizophrenic Disorders: A Replication. The British Journal of Psychiatry, 121, 241-258. 
https://doi.org/10.1192/bjp.121.3.241

Brown, G. W., Monck, E. M., Carstairs, G. M., \& Wing, J. K. (1962). Influence of Family Life on the Course of Schizophrenic Illness. British Journal of Preventive \& Social Medicine, 16, 55-68. https://www.ncbi.nlm.nih.gov/pmc/articles/PMC1058855/ https://doi.org/10.1136/jech.16.2.55

Buitelaar, J. K., Wilens, T. E., Zhang, S., Ning, Y., \& Feldman, P. D. (2009). Comparison of Symptomatic versus Functional Changes in Children and Adolescents with ADHD during Randomized, Double-Blind Treatment with Psychostimulants, Atomoxetine, or Placebo. Journal of Child Psychology and Psychiatry, 50, 335-342. https://doi.org/10.1111/j.1469-7610.2008.01960.x

Conners, C. K., Erhardt, D., \& Sparrow, E. (1999). Conners' Adult ADHD Rating Scales (CAARS) Technical Manual. North Tonawanda, NY: Multi-Health Systems, Inc.

da Silva, M. A., Chaim, T. M., Cavalett, M., Serpa, M. H., Zanetti, M. V., Vieira, G. F. et al. (2014). Health-Related Quality of Life in Adults with Attention-Deficit and Hyperactivity Disorder. Medical Express, 1, 43-46. https://doi.org/10.5935/MedicalExpress.2014.01.10

Daley, D., Sonuga-Barke, E. J., \& Thompson, M. (2003). Assessing Expressed Emotion in Mothers of Preschool AD/HD Children: Psychometric Properties of a Modified Speech Sample. British Journal of Clinical Psychology, 42, 53-67.

Danckaerts, M., Sonuga-Barke, E. J., Banaschewski, T., Buitelaar, J., Döpfner, M., Hollis, C. et al. (2010). The Quality of Life of Children with Attention Deficit/Hyperactivity Disorder: A Systematic Review. European Child and Adolescent Psychiatry, 19, 83-105. https://doi.org/10.1007/s00787-009-0046-3

Edel, M.-A., Juckel, G., \& Brüne, M. (2010). Interaction of Recalled Parental ADHD Symptoms and Rearing Behavior with Current Attachment and Emotional Dysfunction in Adult Offspring with ADHD. Psychiatry Research, 178, 137-141. https://doi.org/10.1016/j.psychres.2010.04.004

Endicott, J., Nee, J., Harrison, W., \& Blumenthal, R. (1993). Quality of Life Enjoyment and Satisfaction Questionnaire: A New Measure. Psychopharmacology Bulletin, 29, 321-326.

Epstein, J. N., \& Kollins, S. H. (2006). Psychometric Properties of an Adult ADHD Diagnostic Interview. Journal of Attention Disorders, 9, 504-514. https://doi.org/10.1177/1087054705283575

Faraone, S. V., Biederman, J., \& Mick, E. (2006). The Age-Dependent Decline of Attention Deficit Hyperactivity Disorder: A Meta-Analysis of Follow-Up Studies. Psychological Medicine, 36, 159-165. https://doi.org/10.1017/S003329170500471X

Fields, S. A., Johnson, W. M., \& Hassig, M. B. (2017). Adult ADHD: Addressing a Unique Set of Challenges. The Journal of Family Practice, 66, 68-74.

https://www.ncbi.nlm.nih.gov/pubmed/28222452

Finzi-Dottan, R., Manor, I., \& Tyano, S. (2006). ADHD, Temperament, and Parental Style as Predictors of the Child's Attachment Patterns. Child Psychiatry \& Human Development, 37, 103-114. https://doi.org/10.1007/s10578-006-0024-7

Gingrich, B., Liu, Y., Cascio, C., Wang, Z., \& Insel, T. R. (2000). Dopamine D2 Receptors in the Nucleus Accumbens Are Important for Social Attachment in Female Prairie Voles (Microtus ochrogaster). Behavioral Neuroscience, 114, 173-183. https://doi.org/10.1037/0735-7044.114.1.173

Ginsberg, Y., Hirvikoski, T., \& Lindefors, N. (2010). Attention Deficit Hyperactivity Disorder (ADHD) among Longer-Term Prison Inmates Is a Prevalent, Persistent and Disabling Disorder. BMC Psychiatry, 10, Article No. 112. 
https://doi.org/10.1186/1471-244X-10-112

Giorgi, A. (2008). Difficulties Encountered in the Application of the Phenomenological Method in the Social Sciences. Indo-Pacific Journal of Phenomenology, 8, 1-9. https://doi.org/10.1080/20797222.2008.11433956

Glaser, B. J., \& Strauss, A. L. (1965). Awareness of Dying. Chicago, IL: Aldine.

Glaser, B., \& Strauss, A. (1967). The Discovery of Grounded Theory. London: Weidenfeld and Nicolson.

Goldberg, S., Muir, R., \& Kerr, J. (2000). Attachment Theory: Social, Developmental and Clinical Perspectives. New York: Routledge.

Green, J., Stanley, C., \& Peters, S. (2007). Disorganized Attachment Representation and Atypical Parenting in Young School Age Children with Externalizing Disorder. Attachment \& Human Development, 9, 207-222.

https://doi.org/10.1080/14616730701453820

Guyatt, G. H., Feeny, D. H., \& Patrick, D. L. (1993). Measuring Health-Related Quality of Life. Annals of Internal Medicine, 118, 622-629. https://doi.org/10.7326/0003-4819-118-8-199304150-00009

Hansson Halleröd, S. L., Anckarsäter, H., Råstam, M., \& Hansson Scherman, M. (2015). Experienced Consequences of Being Diagnosed with ADHD as an Adult-A Qualitative Study. BMC Psychiatry, 15, Article No. 31.

https://doi.org/10.1186/s12888-015-0410-4

Healey, J. H., Nikolic, Z. G., Athanasian, E., \& Boland, P. J. (1997). Quality of Life as Defined by Orthopedic Oncology Patients. Annals of Surgical Oncology, 4, 591-596. https://doi.org/10.1007/BF02305542

Henry, E., \& Jones, S. H. (2011). Experiences of Older Adult Women Diagnosed with Attention Deficit Hyperactivity Disorder. Journal of Women \& Aging, 23, 246-262. https://doi.org/10.1080/08952841.2011.589285

Hinshaw, S. P. (1992). Academic Underachievement, Attention Deficits, and Aggression: Comorbidity and Implications for Intervention. Journal of Consulting and Clinical Psychology, 60, 893-903. https://doi.org/10.1037/0022-006X.60.6.893

Holland, R., Moretti, M. M., Verlaan, V., \& Peterson, S. (1993). Attachment and Conduct Disorder: The Response Program. The Canadian Journal of Psychiatry, 38, 420-431. https://doi.org/10.1177/070674379303800608

Hooley, J. M. (1985). Expressed Emotion: A Review of the Critical Literature. Clinical Psychology Review, 5, 119-139. https://doi.org/10.1016/0272-7358(85)90018-2

Kessler, R. C., Berglund, P., Demler, O., Jin, R., Merikangas, K. R., \& Walters, E. E. (2005). Lifetime Prevalence and Age-of-Onset Distributions of DSM-IV Disorders in the National Comorbidity Survey Replication. Archives of General Psychiatry, 62, $593-$ 602. https://doi.org/10.1001/archpsyc.62.6.593

Kissgen, R., Krischer, M., Kummetat, V., Spiess, R., Scheiffer, R., \& Sevecke, K. (2009). Attachment Representation in Mothers of Children with Attention Deficit Hyperactivity Disorder. Psychopathology, 42, 201-208. https://doi.org/10.1159/000209333

Kolar, D., Keller, A., Golfinopoulos, M., Cumyn, L., Syer, C., \& Hechtman, L. (2008). Treatment of Adults with Attention-Deficit/Hyperactivity Disorder. Neuropsychiatric Disease and Treatment, 4, 107-121. https://www.ncbi.nlm.nih.gov/pubmed/18728812 https://doi.org/10.2147/NDT.S1747

Lakatos, K., Nemoda, Z., Toth, I., Ronai, Z., Ney, K., Sasvari-Szekely, M., \& Gervai, J. (2002). Further Evidence for the Role of the Dopamine D4 Receptor (DRD4) Gene in Attachment Disorganization: Interaction of the Exon III 48-bp Repeat and the -521 
C/T Promoter Polymorphisms. Molecular Psychiatry, 7, 27-31. https://doi.org/10.1038/sj.mp.4000986

Landgraf, J. M. (2007). Monitoring Quality of Life in Adults with ADHD. Journal of Attention Disorders, 11, 351-362. https://doi.org/10.1177/1087054707299400

Leidy, N. K., Revicki, D. A., \& Genesté, B. (1999). Recommendations for Evaluating the Validity of Quality of Life Claims for Labeling and Promotion. Value in Health, 2, 113 127. https://doi.org/10.1046/j.1524-4733.1999.02210.x

Lin, Y.-J., Lo, K.-W., Yang, L.-K., \& Gau, S. S.-F. (2015). Validation of DSM-5 Age-of-Onset Criterion of Attention Deficit/Hyperactivity Disorder (ADHD) in Adults: Comparison of Life Quality, Functional Impairment, and Family Function. Research in Developmental Disabilities, 47, 48-60. https://doi.org/10.1016/j.ridd.2015.07.026

Magnússon, P., Smári, J., Sigurdardóttir, D., Baldursson, G., Sigmundsson, J., Kristjánsson, K. et al. (2006). Validity of Self-Report and Informant Rating Scales of Adult ADHD Symptoms in Comparison with a Semistructured Diagnostic Interview. Journal of Attention Disorders, 9, 494-503. https://doi.org/10.1177/1087054705283650

Mattos, P., Louzã, M. R., Palmini, A. L. F., de Oliveira, I. R., \& Rocha, F. L. (2012). A Multicenter, Open-Label Trial to Evaluate the Quality of Life in Adults with ADHD Treated with Long-Acting Methylphenidate (OROS MPH): Concerta Quality of Life (CONQoL) Study. Journal of Attention Disorders, 17, 444-448. https://doi.org/10.1177/1087054711434772

McCleod, J. (2001). Qualitative Research in Counselling and Psychotherapy. Thousand Oaks, CA: Sage Publications Ltd. https://doi.org/10.4135/9781849209663

Mehringer, A. M., Downey, K. K., Schuh, L. M., Pomerleau, C. S., Snedecor, S. M., \& Schbiner, H. (2002). The Assessment of Hyperactivity and Attention (AHA): Development and Preliminary Validation of a Brief Self-Assessment of Adult ADHD. Journal of Attention Disorders, 5, 223-231. https://doi.org/10.1177/108705470100500404

Michielsen, M., de Kruif, J. T. C. M., Comijs, H. C., van Mierlo, S., Semeijn, E. J., Beekman, A. T. F. et al. (2015). The Burden of ADHD in Older Adults: A Qualitative Study. Journal of Attention Disorders, 22, 591-600. https://doi.org/10.1177/1087054715610001

Mick, E., Faraone, S. V., Spencer, T., Zhang, H. F., \& Biederman, J. (2008). Assessing the Validity of the Quality of Life Enjoyment and Satisfaction Questionnaire-Short Form in Adults with ADHD. Journal of Attention Disorders, 11, 504-509. https://doi.org/10.1177/1087054707308468

Murphy, K. R., \& Adler, L. A. (2004). Assessing Attention-Deficit/Hyperactivity Disorder in Adults: Focus on Rating Scales. The Journal of Clinical Psychiatry, 65, 12-17.

Musser, E. D., Karalunas, S. L., Dieckmann, N., Peris, T. S., \& Nigg, J. T. (2016). Attention-Deficit/Hyperactivity Disorder Developmental Trajectories Related to Parental Expressed Emotion. Journal of Abnormal Psychology, 125, 182-195.

https://doi.org/10.1037/abn0000097

Niederhofer, H. (2009). Attachment as a Component of Attention-Deficit Hyperactivity Disorder. Psychological Reports, 104, 645-648. https://doi.org/10.2466/pr0.104.2.645-648

Nylander, L., Holmqvist, M., Gustafson, L., \& Gillberg, C. (2009). ADHD in Adult Psychiatry. Minimum Rates and Clinical Presentation in General Psychiatry Outpatients. Nordic Journal of Psychiatry, 63, 64-71. https://doi.org/10.1080/08039480802416323

Peris, T. S., \& Hinshaw, S. P. (2003). Family Dynamics and Preadolescent Girls with ADHD: The Relationship between Expressed Emotion, ADHD Symptomatology, and Comorbid Disruptive Behavior. Journal of Child Psychology and Psychiatry, 44, 11771190. https://doi.org/10.1111/1469-7610.00199 
Pidgeon, N. (1996). Grounded Theory: Theoretical Background. Leicester: British Psychological Society Books.

Psychogiou, L., Daley, D. M., Thompson, M. J., \& Sonuga-Barke, E. J. (2007). Mothers' Expressed Emotion toward Their School-Aged Sons. Associations with Child and Maternal Symptoms of Psychopathology. European Child and Adolescent Psychiatry, 16, 458-464. https://doi.org/10.1007/s00787-007-0619-y

Reiner, I., \& Spangler, G. (2010). Adult Attachment and Gene Polymorphisms of the Dopamine D4 Receptor and Serotonin Transporter (5-HTT). Attachment \& Human Development, 12, 209-229. https://doi.org/10.1080/14616731003759674

Robins, L. N., \& Regier, D. A. (1991). Psychiatric Disorders in America: The Epidemiologic Catchment Area Study. New York: The Free Press.

Rösler, M., Ginsberg, Y., Arngrim, T., Adamou, M., Niemelä, A., Dejonkheere, J. et al. (2013). Correlation of Symptomatic Improvements with Functional Improvements and Patient-Reported Outcomes in Adults with Attention-Deficit/Hyperactivity Disorder Treated with OROS Methylphenidate. The World Journal of Biological Psychiatry, 14, 282-290. https://doi.org/10.3109/15622975.2011.571283

Safren, S. A., Sprich, S. E., Cooper-Vince, C., Knouse, L. E., \& Lerner, J. A. (2010). Life Impairments in Adults with Medication-Treated ADHD. Journal of Attention Disorders, 13, 524-531. https://doi.org/10.1177/1087054709332460

Schachar, R., Taylor, E., Wieselberg, M., Thorley, G., \& Rutter, M. (1987). Changes in Family Function and Relationships in Children Who Respond to Methylphenidate. Journal of the American Academy of Child \& Adolescent Psychiatry, 26, 728-732. https://doi.org/10.1097/00004583-198709000-00019

Sonuga-Barke, E. J. S., Lasky-Su, J., Neale, B. M., Oades, R., Chen, W., Franke, B. et al. (2008). Does Parental Expressed Emotion Moderate Genetic Effects in ADHD? An Exploration Using a Genome Wide Association Scan. American Journal of Medical Genetics Part B: Neuropsychiatric Genetics, 147B, 1359-1368. https://doi.org/10.1002/ajmg.b.30860

Steele, M., Jensen, P. S., \& Quinn, D. M. P. (2006). Remission versus Response as the Goal of Therapy in ADHD: A New Standard for the Field? Clinical Therapeutics, 28, $1892-$ 1908. https://doi.org/10.1016/j.clinthera.2006.11.006

Storebø, O. J., Ramstad, E., Krogh, H. B., Nilausen, T. D., Skoog, M., Holmskov, M. et al. (2015). Methylphenidate for Children and Adolescents with Attention Deficit Hyperactivity Disorder (ADHD). Cochrane Database of Systematic Reviews, No. 11, Cd009885. https://doi.org/10.1002/14651858.CD009885.pub2

Taylor, A., Deb, S., \& Unwin, G. (2011). Scales for the Identification of Adults with Attention Deficit Hyperactivity Disorder (ADHD): A Systematic Review. Research in Developmental Disabilities, 32, 924-938. https://doi.org/10.1016/j.ridd.2010.12.036

Weiss, M., Childress, A., Mattingly, G., Nordbrock, E., Kupper, R. J., \& Adjei, A. L. (2018). Relationship between Symptomatic and Functional Improvement and Remission in a Treatment Response to Stimulant Trial. Journal of Child and Adolescent Psychopharmacology, 28, 521-529. https://doi.org/10.1089/cap.2017.0166

Wender, P. H. (1995). Attention-Deficit Hyperactivity Disorder in Adults. New York: Oxford University Press. 